\title{
Redox Flow Batteries, Hydrogen and Distributed Storage
}

\author{
C. R. Dennisona, Heron Vrubel ${ }^{a}$, Véronique Amstutza ${ }^{a}$ Pekka Peljo ${ }^{a}$, Kathryn E. Toghill ${ }^{b}$, \\ and Hubert H. Girault ${ }^{\star a}$
}

\begin{abstract}
Social, economic, and political pressures are causing a shift in the global energy mix, with a preference toward renewable energy sources. In order to realize widespread implementation of these resources, large-scale storage of renewable energy is needed. Among the proposed energy storage technologies, redox flow batteries offer many unique advantages. The primary limitation of these systems, however, is their limited energy density which necessitates very large installations. In order to enhance the energy storage capacity of these systems, we have developed a unique dual-circuit architecture which enables two levels of energy storage; first in the conventional electrolyte, and then through the formation of hydrogen. Moreover, we have begun a pilot-scale demonstration project to investigate the scalability and technical readiness of this approach. This combination of conventional energy storage and hydrogen production is well aligned with the current trajectory of modern energy and mobility infrastructure. The combination of these two means of energy storage enables the possibility of an energy economy dominated by renewable resources.
\end{abstract}

Keywords: Electrical energy storage $\cdot$ Hydrogen $\cdot$ Redox flow batteries

\section{Introduction}

\subsection{Growing Challenges for the Electrical Grid}

Around the world, concerns about energy security, sustainability, and the environment have prompted a re-evaluation of the ways in which we produce and consume (or more precisely, convert) energy. As a result, there is a growing effort to transition the global energy mix from conventional sources, such as fossil fuels and nuclear energy, to more sustainable sources such as hydro, wind and solar. Indeed, from 2002 to 2012, the net renewable electricity generation worldwide increased by $62.5 \% .^{[1]}$ As of 2013, 25.4\% of European electricity, and $13.6 \%$ of overall energy (including transport, electricity, and heating/cooling) was derived from renewable

\footnotetext{
${ }^{\star}$ Correspondence: Prof. Dr. H. H. Girault ${ }^{\mathrm{a}}$

E-mail: hubert.girault@epfl.ch

aLaboratoire d'Electrochimie Physique et Analytique (LEPA)

École Polytechnique Fédérale de Lausanne (EPFL) Valais Wallis

Rue de l'Industrie 17

Case Postale 440

$\mathrm{CH}-1951$ Sion

bDepartment of Chemistry

Lancaster University

Lancaster

LA1 4YB, United Kingdom
}

resources. ${ }^{[2]}$ Moreover, these values are set to grow significantly in the coming years. By 2020, the European Union is targeting $20 \%$ reliance on renewables for its overall energy mix. ${ }^{[3]}$ These targets are primarily being met through the installation of wind, photovoltaic, and concentrated solar generation facilities. However, the growing penetration of electric vehicles also plays a key role in shifting the energy mix by reducing the need for petroleum.

While these changes to the energy mix represent significant progress toward social, environmental, and political goals, they also represent a growing challenge for the world's electrical grids. Currently, most electrical grids are designed to produce electricity 'just in time' - as additional load is added to the grid, generating stations must simultaneously ramp up to meet the demand and keep the grid voltage and frequency stable. As consumer demand is inherently unpredictable, some 'reserve' generation capacity needs to be available at all times to cope with large increases in demand. This reserve capacity has traditionally taken the form of redundant generating stations which are idle, but synchronized with the grid so that they can react immediately (so called 'spinning reserve'). These resources are both inefficient and costly, as they are spinning (i.e. consuming fuel), but primarily operating at zero-load. Nonetheless, this model for the electrical grid is quite satisfactory for coping with highly variable demand for electricity, provided that the supply of electricity is reliable. However, with the growing implementation of renewable resources such as wind and solar, this assumption is rapidly losing its validity. ${ }^{[4]}$

For grids with a large penetration of renewable energy, both supply and demand become unpredictable. Solar irradiation can vary significantly from minute to minute depending on cloud formations and other atmospheric conditions. A passing cloud can cause megawatts of solar generation to suddenly disappear from the grid, necessitating other generating stations to rapidly ramp up their output to maintain the stability of the grid. As the cloud passes, the solar generation becomes available again, requiring the other generating stations to suddenly curtail their output to compensate. The availability of wind is equally unpredictable. If these fluctuations are not compensated for, the power quality (i.e. line voltage and frequency) on the grid can deteriorate, eventually causing localized or even cascading power outages. As the energy mix continues to evolve, favouring renewable resources, these fluctuations will become increasingly disruptive, pushing beyond the ramping limitations of conventional power stations. A larger share of 'spinning reserves', primarily gas-fired generators, will need to be allocated to stabilize the system. In effect, this means that it becomes increasingly necessary to burn fossil fuels simply to utilize renewable energy sources, and of course this largely undermines the goal of using renewable energy in the first place (e.g. reduced dependence on fossil fuels, reduced atmospheric emissions, etc.).

The growing use of electric vehicles can create similar problems of grid insta- 
bility. Owners of these vehicles expect to be able to recharge in a timeframe which is reasonably similar to conventional liquid-fuelled vehicles. These quick charging stations can easily consume over $100 \mathrm{~kW}$ each, and charging may take up to an hour or more. Moreover, drivers will expect to be able to charge whenever necessary, creating a large magnitude, unpredictable load on the grid. Finally, each driver who replaces a petroleum-fuelled vehicle with an electric vehicle is essentially shifting load from the petroleum infrastructure to the electrical grid. This will increase the total load on the electrical grid, which will not only require additional generators, but will also tax the electrical transmission and distribution infrastructure. As the infrastructure reaches its limits, blackouts will become increasingly common. ${ }^{[4]}$

Hydrogen-fuelled vehicles have been considered as an alternative to fossilfuelled vehicles for years. Unfortunately, however, hydrogen is commonly obtained by reforming fossil fuels, resulting in hydrogen which is not truly 'clean' (in the sense of being carbon neutral). Electrolysers may be used to obtain hydrogen by water splitting. Currently, however, the electricity used to drive the electrolysis comes from fossil fuel and nuclear resources, again undermining the advantages of this approach. Moreover, common alkaline electrolysers are not very tolerant of highly variable, intermittent operation, making them somewhat incompatible with most renewable resources. Polymer electrolyte membrane (PEM) electrolysers are more capable of coping with an intermittent power supply, but they require large amounts of precious metal catalysts (e.g. Pt and Ir), making them very costly. Finally, the lack of a hydrogen distribution infrastructure has largely undermined efforts to transition to a 'clean' hydrogen energy economy.

The current grid architecture is able to tolerate the existing level of unpredictability on the demand side. However, the present trajectory of energy production and consumption will significantly stress the system in the coming years. Fundamentally, the notion of 'just-in-time' electricity production is incompatible with unpredictable energy sources, such as wind and solar, and large, unpredictable loads, such as electric vehicles. In order to achieve the energy goals of this decade, a more flexible grid infrastructure is needed, and the key to achieving this flexibility will be largescale electrical energy storage. ${ }^{[4]}$

\subsection{The Role of Energy Storage in Tomorrow's Electrical Grid}

An electrical grid with a large amount of energy storage capacity moves away from the paradigm of 'just-in-time' energy production by essentially decoupling energy production from consumption. Instead, such a grid operates on an 'as available' or 'on demand' basis - energy is stored whenever it is available from the generation infrastructure, and supplied to consumers according to demand. In effect, the energy storage infrastructure acts as a buffer between generation and consumption. ${ }^{[5]}$ This buffering is critical for the next evolution of the electrical grid for two reasons; it protects consumers from variability in generation (e.g. clouds passing over a solar station), and it protects generators from large variability in demand (e.g. electric vehicle charging). Thus, grid-scale energy storage is necessary to enable the widespread implementation of renewable energy sources and electric vehicles.

However, there are numerous additional benefits to electrical energy storage. Such systems can be used to offset the 'peaks' in electrical demand. In such a regime, energy is stored when demand is low, and then time-shifted to periods when demand is high. Large electrical consumers (e.g. steel mills) may engage in this practice to reduce their peak demand (known as 'peak shaving'), and the accompanying demand charges. Meanwhile, electrical generators may do the same in order to reduce their perceived load (known as 'load levelling'), thereby avoiding the need to start up costly peak generating units. Additionally, small independent power producers may utilize energy storage assets to capitalize on fluctuations in the price of electricity (a practice known as 'energy arbitrage'). Grid operators may use electrical energy storage to help regulate voltage and frequency on the grid. Moreover, energy storage installations may be placed downstream of congested transmission lines, and used to alleviate that congestion in a manner similar to load levelling. In some cases, this strategy allows grid operators to defer transmission line upgrades which would otherwise be necessary to serve peak demand for only a few hours per day. ${ }^{[4]}$

All of these applications give rise to a growing market, which promises to be quite large in the coming years. According to Deutsche Bank Research, in the next twenty years approximately 30 billion Euro will be invested in electrical energy storage infrastructure within Germany alone. ${ }^{[6]}$ By 2040, they estimate that 40 TWh of storage will be required to cope with the expected surpluses. At the global scale, Citi Group estimates that the global market for energy storage will reach $240 \mathrm{GW}$, amounting to a market size of more than 400 billion USD. ${ }^{[7]}$ It is interesting to note the different orders of magnitude between the projected power (GW) and energy (TWh) requirements for future energy storage systems. It is clear that from a market perspective, the value of these systems lies in their energy capacity.

Several technologies are being considered to address the growing technical needs and market opportunities. Indeed, from a technological standpoint largescale electrical energy storage is not a new concept. Large pumped hydroelectric stations have long been used to store energy by pumping water from a low elevation to a higher elevation. To recover this energy, the water is allowed to flow downhill under the influence of gravity, passing through a turbine along the way. Unfortunately, this approach is highly geographically constrained, as it typically requires existing natural features such as mountain lakes to be practical. ${ }^{[5,8]}$ In a similar approach, air is compressed into a reservoir to store energy, and allowed to expand through a turbine to recover the energy. These systems tend to be quite large, and have a relatively low efficiency due to heat rejection during the compression step..$^{5,8]}$ Instead, it is desirable to have an efficient, scalable, flexible technology that can be deployed to a variety of locations.

Various other technologies, such as high energy flywheels, semiconducting magnetic energy storage, and electrochemical capacitors have been proposed as well. While these systems are relatively modular and suitable for power conditioning applications, they do not provide the energy capacity needed to time-shift the energy produced by renewable resources. ${ }^{[5,8]}$ Instead, electrochemical systems appear to be the most promising for these applications.

Several battery technologies are currently being considered and demonstrated for grid-scale deployment. ${ }^{[9]}$ High-temperature sodium sulfur batteries provide high energy density and relatively long lifetime. However, these systems must operate at high temperatures $\left(250-350{ }^{\circ} \mathrm{C}\right)$ in order to maintain conductivity. Large, containerized arrays of lithium ion batteries have also been proposed and demonstrated. These systems are very sensitive to temperature, and thus require good auxiliary thermal management systems. Moreover, very complex battery management systems are required to keep all of the individual cells balanced and prevent overcharging. Perhaps the largest concerns, however, are safety and cost. Even the recently released Tesla Powerwall costs between 350 and $430 \mathrm{USD} / \mathrm{kWh},{ }^{[10]}$ falling short of the U.S. Department of Energy target of 100 USD/ kWh. ${ }^{[11]}$ Moreover, the serious fire hazard presented by these batteries is well known at the small scale. ${ }^{[12]}$ For a grid-scale installation, the results could be catastrophic. For these reasons, one of the most promising candidates for grid-scale energy storage is the redox flow battery. 


\section{Redox Flow Batteries}

A redox flow battery $(\mathrm{RFB})$ is a type of secondary battery system in which charge is stored and released by oxidizing or reducing active species in a flowing solution. The active species remain solubilized in the surrounding electrolyte during operation. During charging, the electrolyte is pumped through an electrochemical cell, consisting of two electrodes separated by an ion-exchange membrane (Fig. 1). Current is supplied to the electrodes via conductive current collectors, polarizing the electrodes. As a result of polarization, redox reactions occur at the surfaces of the electrodes, resulting in the oxidation (positive half-cell) and reduction (negative half-cell) of the active species dissolved in electrolytes. These charged electrolytes then pass out of the electrochemical cell and into storage reservoirs. To discharge the system and recover the stored energy, the electrochemical process is reversed.[13]

The unique aspect of RFBs is their system architecture consisting of a central electrochemical cell/stack and external tanks. In conventional batteries, the active material is stored within the cell itself; in effect coupling the power output and energy capacity. By storing the electrolytes externally, the energy capacity can be scaled arbitrarily by increasing the volume of stored electrolytes. Similarly, the power output of RFB systems is determined by the cell area. This decoupling of power and energy makes RFBs highly scalable and flexible, which in turn makes them uniquely suited for grid-scale applications. ${ }^{[13]}$

The specific redox chemistry is another key aspect of these systems. The redox chemistry determines the maximum energy density (according to the solubility of the active species) and the typical operating voltage. Numerous redox chemistries have been proposed and demonstrated. Among the most common are: $\mathrm{Fe} / \mathrm{Cr}, \mathrm{Zn} /$ $\mathrm{Br}$, and all-vanadium $(\mathrm{V} / \mathrm{V})$. Other chemistries involving two-phase processes also exist: all-iron $(\mathrm{Fe} / \mathrm{Fe})$, all-copper $(\mathrm{Cu} / \mathrm{Cu})$, $\mathrm{H} / \mathrm{Br}$, V/air, etc. ${ }^{[13-18]}$

Among the numerous redox chemistries that can be utilized in an RFB architecture, the all-vanadium chemistry is perhaps the most prototypical. We consider it here, as an illustrative example. In a vanadium redox flow battery (VRFB), V(IV) is oxidized to $\mathrm{V}(\mathrm{V})$ in the positive half-cell during charging, while V(III) is reduced to $\mathrm{V}$ (II) on the negative half-cell:

$$
\mathrm{V}(\mathrm{IV}) \rightleftharpoons \mathrm{V}(\mathrm{v})+e^{-}, E^{\circ}=0.991 \mathrm{~V}
$$

$\mathrm{V}(\mathrm{III})+e^{-} \rightleftharpoons \mathrm{V}(\mathrm{II}), E^{\circ}=-0.255 \mathrm{~V}$

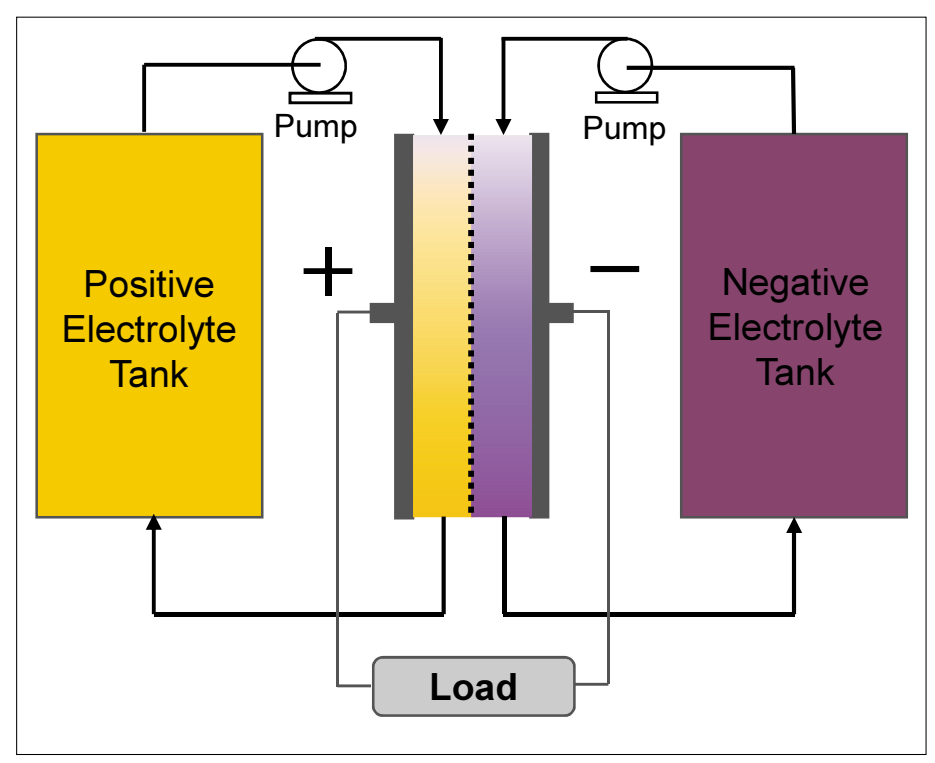

Fig. 1. System architecture for conventional flow batteries based on liquid electrolytes.

Protons conduct the current through the membrane; upon charge a number of protons equal to the number of transferred electrons are transferred from the positive electrolyte into the negative electrolyte. Upon discharge, the opposite reactions occur. The standard cell potential is $c a .1 .25 \mathrm{~V}$. The active vanadium species are typically dissolved in an aqueous supporting electrolyte containing sulfuric acid, although other acids, such as methanesulfonic acid and hydrochloric acid have also been used.[19] Since both half-cells are based on vanadium active species, cross-contamination between the two half-cells is not a major concern. In effect, unintentional mixing of the two electrolyte streams results in a chemical discharge and subsequent loss of stored energy, but does not otherwise degrade the solutions. ${ }^{[13-17]}$

Regardless of the composition of the electrolyte, the maximum energy density of the system is typically determined by the limits of solubility of the active species. In practice, the concentration of active species is limited from 1 to $2 \mathrm{M}$, yielding an achievable energy density of approximately 25 to 40 Wh per litre of electrolyte. [13-17] This is the main technical limitation of modern flow battery systems - the energy density is intrinsically limited by the solubility of the active species.

Significant effort has been placed on enhancing the solubility of the various active species in solution. In particular, previous work has focused on improving solubility by changing the composition of the supporting electrolyte[19-22] and introducing various additives.[23-27] Although significant progress has been made, these approaches are unlikely to yield disruptive improvements in energy density. Moreover, they are highly dependent on the specific chemistry, and thus cannot be readily generalized to other redox chemistries.

\section{Dual-Circuit Redox Flow Battery}

\subsection{Two Levels of Energy Storage}

The dual-circuit redox flow battery was developed in order to bypass the energy density limitations of conventional RFBs, by adding a second 'level' of energy storage.[28,29] Energy may be stored conventionally, in the liquid electrolyte, or converted to hydrogen gas through indirect electrolysis of water. This design allows energy exceeding the conventional capacity of the battery to still be captured and stored in the form of hydrogen. The energy stored within the hydrogen may be returned to the electrical grid using stationary fuel cells, or used to power fuel cell vehicles, to enrich natural gas, or in other industrial processes. In this way, excess energy is never wasted. This approach enables continuous storage of surplus renewable energy, even when the conventional storage capacity of the battery has been reached. Moreover, this approach eliminates the need to oversize the battery.

In order to accomplish this, a secondary flow circuit was added to each half of the redox flow battery architecture (Fig. 2). On the negative half-cell, the secondary flow circuit contains a catalytic reactor where the negative electrolyte is chemically discharged, producing hydrogen gas according to Eqn. (3):

$2 \mathrm{H}^{+}+2 \mathrm{D}^{-} \rightarrow \mathrm{H}_{2}+2 \mathrm{D}$

where $\mathrm{D}^{-}$is an electron donor. The production of hydrogen consumes protons in the electrolyte solution. It is critical to maintain a relatively constant concentration of protons in order to ensure good electrolyte conductivity and maintain the solubility of the active species throughout the cycle. 


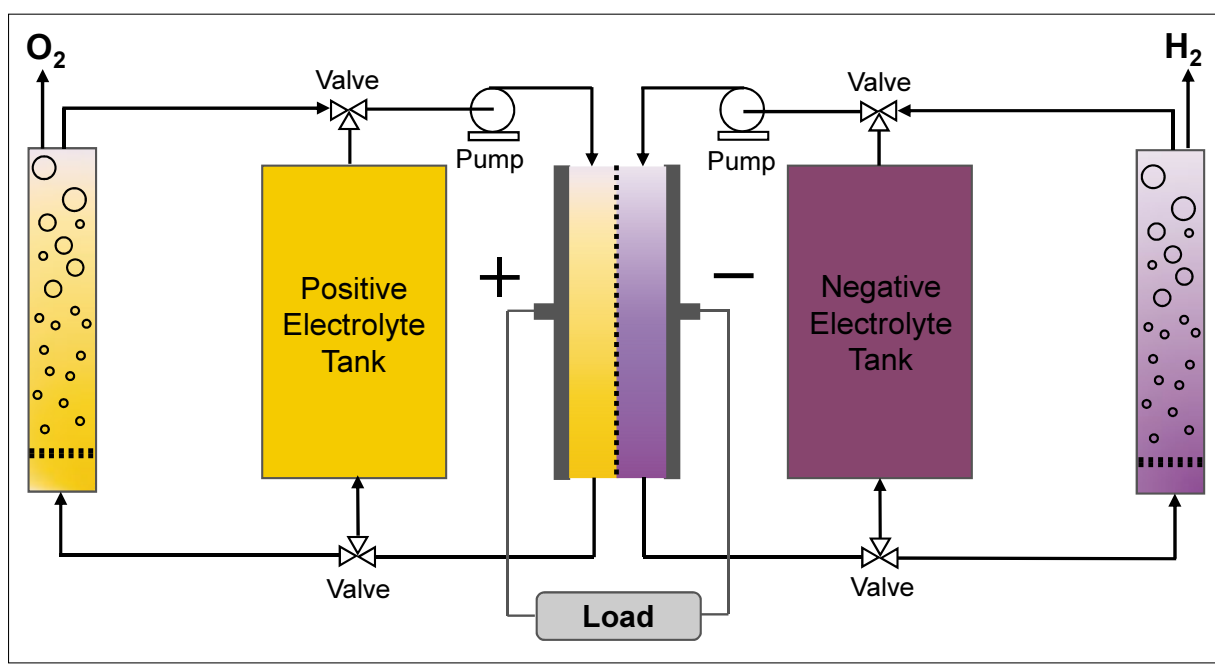

Fig. 2. Dual-circuit redox flow battery architecture. The valves allow electrolyte to pass through the external reactors, where the electrolyte may be chemically discharged 'on demand' to produce hydrogen and oxygen on the negative and positive halves, respectively.

Thus, a source of protons is also needed. These protons are liberated in the positive catalytic reactor via the water oxidation reaction:

$$
2 \mathrm{H}_{2} \mathrm{O}+4 \mathrm{~A}^{+} \rightarrow \mathrm{O}_{2}+4 \mathrm{H}^{+}+4 \mathrm{~A}
$$

where $\mathrm{A}^{+}$is an electron acceptor. The protons liberated by this reaction pass from the positive half-cell to the negative half-cell, via the membrane, providing additional reactant for the hydrogen evolution reaction. Thus, if water is added stoichiometrically, both of these reactions may proceed indefinitely, assuming a constant supply of charged electrolytes. ${ }^{[29]}$

In order to drive these reactions, electrolytes with appropriate redox potentials must be utilized. For the hydrogen evolution reaction (Eqn. (3)), the V(II)/V(III) redox couple (Eqn. (2)) has a thermodynamically favourable redox potential. Unfortunately, the $\mathrm{V}(\mathrm{IV}) / \mathrm{V}(\mathrm{v})$ couple (Eqn. (1)) does not have a sufficient redox potential to drive water oxidation (Eqn. (4)). For this reason, the $\mathrm{Ce}(\mathrm{III}) / \mathrm{Ce}(\mathrm{IV})$ couple was utilized for our proof-of-concept work:

$$
\mathrm{Ce}(\mathrm{IV})+e^{-} \rightleftharpoons \mathrm{Ce}(\mathrm{III}), E^{\circ}=1.72 \mathrm{~V}
$$

Despite sufficient thermodynamic potentials to drive the indirect water electrolysis reactions, catalysts were still needed to enhance the kinetics of the reactions. $\mathrm{RuO}_{2}$ was utilized to drive the water oxidation reaction, due to its suitability in acidic conditions. For the hydrogen evolution reaction, $\mathrm{Mo}_{2} \mathrm{C}$ was utilized. These catalysts lower the overpotential sufficiently to allow both reactions to proceed spontaneously in the presence of the charged electrolytes. [29]

Using the V/Ce redox chemistry, and the catalysts mentioned above, we demon- strated the proof-of-concept at the laboratory scale. ${ }^{[29]}$ Specifically, indirect hydrogen evolution and water oxidation were demonstrated at the surface of $\mathrm{Mo}_{2} \mathrm{C}$ and $\mathrm{RuO}_{2}$, respectively, using the fully charged $\mathrm{V}$ and Ce electrolytes. Moreover, the conversion efficiency and apparent reaction rate for both reactions were determined. The hydrogen evolution reaction, in particular, was found to have nearly $100 \%$ conversion efficiency. ${ }^{[29]}$ Based on the success of this preliminary work, it was decided to begin scaling up the process to a more industrially-relevant scale.

\subsection{Scale-up and Demonstration}

In order to further validate the dual-circuit approach and determine its technical readiness, a demonstration project was undertaken. The basic platform for this development effort was a CellCube $10 \mathrm{~kW} / 40$ $\mathrm{kWh}$ all-vanadium redox flow battery produced by Gildemeister Energy Solutions (Fig. 3b). The battery was installed at a site in Martigny, Valais, Switzerland (Fig. 3a). After installation and commissioning, we began the process of retrofitting the battery with the necessary secondary circuit and catalytic reactor for hydrogen generation. As the commercial RFB is based on the allvanadium redox chemistry, the water oxidation reaction is not possible on the positive half. Accordingly, we have focused our efforts on demonstrating the hydrogen evolution reaction.

One of the key steps in this effort was the development of a catalyst which could be practically employed at this scale. A fixed bed of the microparticulate $\mathrm{Mo}_{2} \mathrm{C}$ catalyst used in our proof-of-concept work would cause too much pressure drop in the secondary hydraulic circuit. Moreover, such small particles could become entrained in the flow of the electrolyte and travel into the electrolyte storage tank, causing un- controlled hydrogen evolution inside the tank. For these reasons, we decided to use a supported catalyst. A spray-coating process was developed to synthesize $\mathrm{Mo}_{2} \mathrm{C}$ on the surface of inert, spherical supports. The spherical supports provide reasonable surface area while maintaining large interstitial voids for electrolyte and gas to flow through. Initially, porous alumina supports were used, however the mechanical stability of the catalytic coating on these spheres was not satisfactory. After several iterations, $3 \mathrm{~mm}$ ceramic beads (Denstone 2000, Saint Gobain, Germany) were found to provide good adhesion and mechanical strength for the catalytic coating.

Having developed a suitable catalyst, the next step was to design the catalytic reactor. Initially, a horizontal fixed bed reactor design was used. Charged electrolyte was injected at one end of the reactor, flowing through the catalytic bed and generating hydrogen. Hydrogen could be collected from the headspace above the catalytic bed. Baffles were installed along the length of the reactor to help promote mixing of the electrolyte throughout the reactor. Unfortunately, this reactor design had problematic mass transport characteristics. The hydrogen evolution reaction caused the electrolyte in the catalytic bed to foam. This foam had sufficient capillarity to block many of the interstitial voids between particles, severely limiting the utilization of the catalyst.

To address this limitation, a new reactor was recently designed and built (Fig. $3 \mathrm{c})$. This reactor is a vertical, multi-stage fixed bed reactor. In each stage, electrolyte is injected at the bottom of the catalytic bed. The liquid then flows up, through the catalytic bed, until reaching the raised outlet and flowing into the next stage (Figs $3 \mathrm{~d}, \mathrm{e})$. The hydrogen gas is collected from the headspace in each stage. In total, the reactor contains eight stages, each containing $c a .2 \mathrm{~g}$ of $\mathrm{Mo}_{2} \mathrm{C}$.

This reactor design has several advantages over the previous reactor design. The large number of stages increases the residence time of the reactor, allowing greater conversion of the electrolyte in a single pass. Moreover, the vertical flow of the electrolyte helps to facilitate the shedding of hydrogen bubbles from the catalytic bed. This helps to prevent blocking of the catalyst, and increases the amount of conversion achieved in each stage.

We have recently started characterizing the performance of this new reactor design. Our initial results indicate that the reactor is very well suited for hydrogen production, and is able to provide a higher conversion rate as a result of the various improvements introduced. It appears that full conversion of the electrolyte may be achieved for flow rates up to $1 \mathrm{~L} /$ minute. At this flow rate, the 

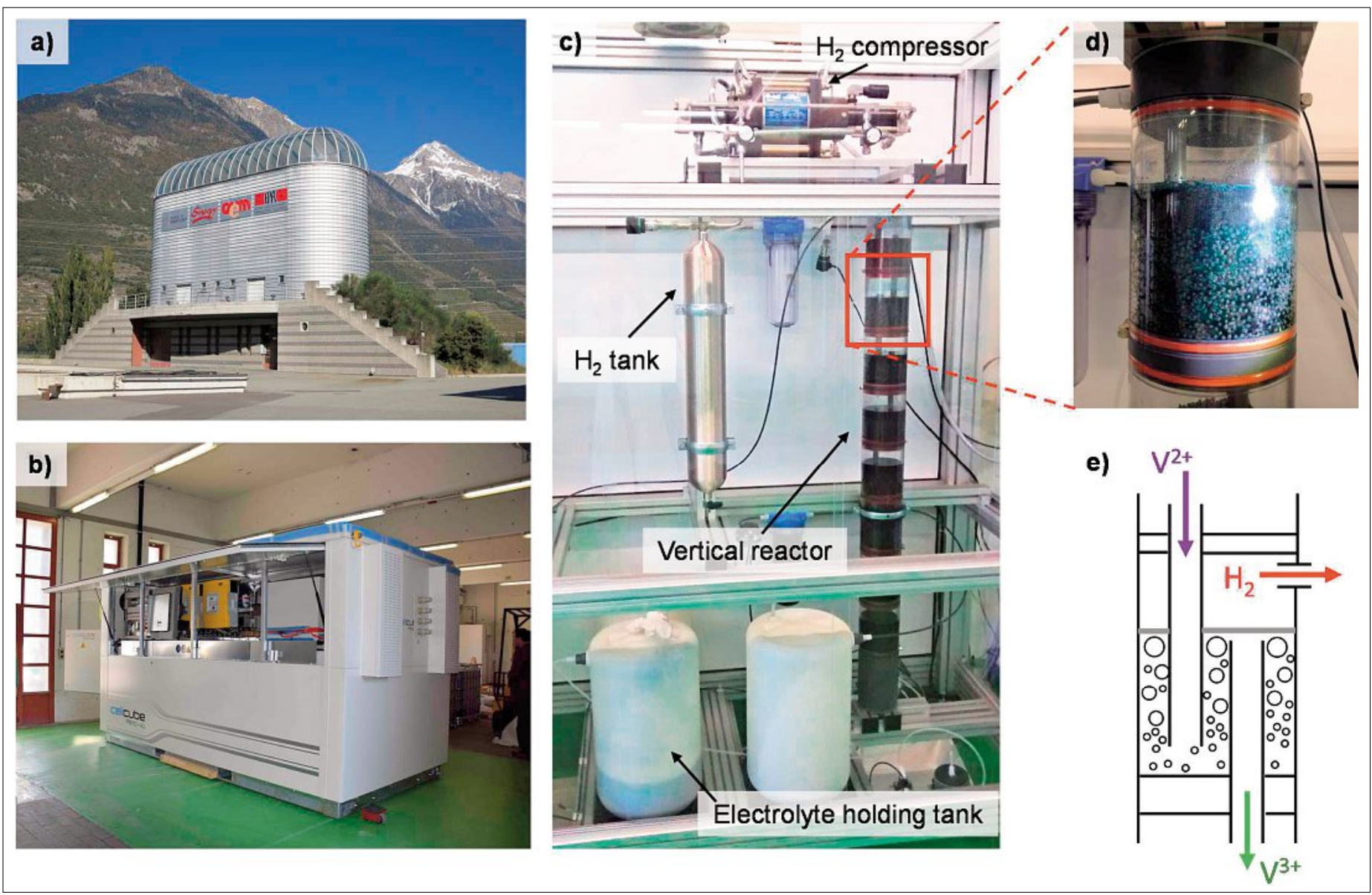

Fig. 3. a) Dual-circuit RFB demonstrator site in Martigny, Valais, Switzerland. The demonstrator is based around b) a $10 \mathrm{~kW} / 40 \mathrm{kWh}$ all-vanadium flow battery which has been retrofitted with c) an auxiliary hydraulic circuit for producing hydrogen. d) The reactor contains eight identical stages, e) where electrolyte is injected at the bottom of the catalytic bed and flows upward through the catalyst before reaching the outlet. Hydrogen is removed from the headspace above each stage.

battery can be completely chemically discharged in 16.7 hours, which is equivalent to a conventional discharge at $c a .2 .4 \mathrm{~kW}$. If a greater equivalent discharge power is needed, several reactors may be placed in parallel.

\section{Looking Forward}

The dual-circuit redox flow battery discussed here provides a unique approach for enhancing the energy capacity of redox flow battery systems. Since this approach does not alter the fundamental RFB architecture, existing systems can be easily retrofitted to enable the production of hydrogen. Moreover, besides indirect water electrolysis, other industrial processes can potentially be accomplished using this system architecture, such as the oxidation of $\mathrm{H}_{2} \mathrm{~S}$ and $\mathrm{SO}_{2}$ to produce sulfuric acid.[30] More generally, the concept of indirect electrolysis could be extended to other electrosynthetic processes, for example for the on-site production of chlorine (chlorine transport through inner cities such as Lausanne being a hazardous process) or for the production of hydrogen peroxide, which is an environmentally friendly oxidant.
In a broader context, this system is representative of the growing importance of diverse energy storage infrastructure. The interplay between hydrogen and electricity will become increasingly important in the coming years. It is clear that large-scale energy storage is needed to facilitate the widespread implementation of renewable energy sources. Growing reliance on electric vehicles will further reinforce this need. For mobile applications, hydrogen energy storage is particularly beneficial due to its high energy density, and the ability to instantly refuel vehicles. However, widespread hydrogen infrastructure is lacking and remains a significant barrier to the acceptance of hydrogen fuelled vehicles.

Nonetheless, we can imagine a future which capitalizes on the synergies between electricity and hydrogen. Energy storage technologies, such as redox flow batteries, may be installed at renewable energy generation sites to buffer supply and demand. Additional energy storage sites may be installed at nodes throughout the distribution system in order to flatten the load on the network and provide greater reliability. As more storage capacity comes online, this will enable further implementation of renewable resources, starting a cycle of constructive feedback for both technologies. Moreover, the overall energy storage capacity available in the grid will make it more tolerant to the large amplitude perturbations caused by the charging of battery electric vehicles. Some of these distributed energy storage sites may also function as fuelling sites for hydrogen fuelled vehicles. Hydrogen can be produced directly on-site by electrolysis of water, avoiding the need for a hydrogen distribution infrastructure. In some cases, indirect water electrolysis, as seen in the dual-circuit flow battery system presented here, may be utilized. However, conventional RFBs can also be used as a buffer between renewable resources and conventional electrolysers, allowing the electrolyser to operate at a constant load. In both cases, the electricity used to drive the electrolysis will be derived primarily from renewable resources, rather than fossil fuel or nuclear resources, producing truly 'clean' hydrogen.

A future grid powered solely by renewable energy sources is rapidly becoming possible with ongoing advances in technology. The dual-circuit redox flow battery system can play a key role as an energy management platform, directly connecting the producer's needs to the consumer's re- 
quirements. Its ability to produce hydrogen on demand provides an additional degree of freedom compared to classical batteries, increasing the versatility of large-scale electrochemical energy storage in a renewable energy grid.

Received: August 8, 2015

[1] U.S. Energy Information Administration Online Database, http://www.eia.gov, accessed August 7, 2015.

[2] Eurostat SHARES Online Database - 2013, http://ec.europa.eu/eurostat/web/energy/data/ shares, accessed August 7, 2015.

[3] European Commision, 'Directive 2009/28/EC of the European Parliament and of the Council of 23 April 2009', Official Journal of the European Union, 2009, 140, 16.

[4] Electric Power Research Institute, 'EPRI-DOE Handbook of Energy Storage for Transmission and Distribution Applications', Report No.: 1001834, 2003.

[5] Electric Power Research Institute, 'Electricity Energy Storage Technology Options', Report No.: 1020676, 2010.

[6] J. Auer, J. Keil, 'State-of-the-Art Electricity Storage Systems', in Current Issues, Deutsche Bank Research, 2012

[7] S. Savvantidou, T. Sasaki, A. Yuen, 'Storage Batteries: A Third Growth Market', in Citi GPS: Global Perspectives \& Solutions, Citi Group, 2015.
[8] United States Department of Energy, 'Grid Energy Storage', http://www.sandia.gov/ess/ docs/other/Grid_Energy_Storage_Dec_2013. $p d f, 2013$.

[9] B. Dunn, H. Kamath, J.-M. Tarascon, Science 2011, 334, 928.

[10] Tesla Powerwall, http://www.teslamotors.com/ powerwall, accessed August 9, 2015.

[11] Advanced Research Projects Agency Energy, U.S. Department of Energy, 'GRIDS Program Overview', http://arpa-e.energy.gov/ sites/default/files/documents/files/GRIDS_ ProgramOverview.pdf, 2010.

[12] J. M. Tarascon, M. Armand, Nature 2001, 414, 359.

[13] A. Weber, M. Mench, J. Meyers, P. Ross, J. Gostick, Q. Liu, J. Appl. Electrochem. 2011, 41, 1137.

[14] N. Trung, R. F. Savinell, Electrochem. Soc. Interface 2010, 19, 54.

[15] M. Skyllas-Kazacos, M. H. Chakrabarti, S. A. Hajimolana, F. S. Mjalli, M. Saleem, $J$. Electrochem. Soc. 2011, 158, R55.

[16] G. Kear, A. A. Shah, F. C. Walsh, Int. J. Ener. Res. 2012, 36, 1105

[17] A. Parasuraman, T. M. Lim, C. Menictas, M. Skyllas-Kazacos, Electrochim. Acta 2013, 101, 27.

[18] D. Lloyd, E. Magdalena, L. Sanz, L. Murtomäki, K. Kontturi, J. Power Sources 2015, 292, 87.
[19] M. Vijayakumar, W. Wei, N. Zimin, V. Sprenkle, H. JianZhi, J. Power Sources 2013, 241, 173.

[20] Z. Shudi, Z. Yuchun, Appl. Mech. Mater. 2013, $281,461$.

[21] Y. H. Wen, Y. Xu, J. Cheng, G. P. Cao, Y. S. Yang, Electrochim. Acta 2013, 96, 268.

[22] X. W. Wu, J. Liu, X. J. Xiang, J. Zhang, J. P. Hu, Y. P. Wu, Pure Appl. Chem. 2014, 86, 661.

[23] M. Skyllas-Kazacos, C. Peng, M. Cheng, Electrochem. Solid-State Lett. 1999, 2, 121.

[24] J. Zhang, L. Li, Z. Nie, B. Chen, M. Vijayakumar, S. Kim, W. Wang, B. Schwenzer, J. Liu, Z. Yang, J. Appl. Electrochem. 2011, 41, 1215.

[25] G. Wang, J. Chen, X. Wang, J. Tian, H. Kang, X. Zhu, Y. Zhang, X. Liu, R. Wang, J. Electroanal. Chem. 2013, 709, 31.

[26] Y. Lei, S. Q. Liu, C. Gao, X. X. Liang, Z. X. He, Y. H. Deng, Z. He, J. Electrochem. Soc. 2013, 160, A722.

[27] G. Wang, J. Chen, X. Wang, J. Tian, H. Kang, X. Zhu, Y. Zhang, X. Liu, R. Wang, J. Ener. Chem. 2014, 23, 73.

[28] V. Amstutz, K. E. Toghill, C. Comninellis, H. H. Girault, WO Patent WO2013131838, 2013

[29] V. Amstutz, K. E. Toghill, F. Powlesland, H. Vrubel, C. Comninellis, X. Hu, H. H. Girault, Ener. Environ. Sci. 2014, 7, 2350.

[30] P. Peljo, H. Vrubel, V. Amstutz, J. Pandard, J. Morgado, A. Santasalo-Aarnio, D. Lloyd, F. Gurny, C. R. Dennison, K. E. Toghill, H. H. Girault, Green Chem. 2015, doi:10.1039/ C5GC02196K. 